\title{
Exploring the Design Space for Parent-Child Reading
}

\author{
Yvonne Vezzoli \\ UCL Knowledge Lab \\ London, United Kingdom \\ y.vezzoli@ucl.ac.uk \\ Natalia Kucirkova \\ UCL Knowledge Lab \\ London, United Kingdom \\ n.kucirkova@ucl.ac.uk
}

\author{
Sara Kalantari \\ UCL Knowledge Lab \\ London, United Kingdom \\ s.kalantari@ucl.ac.uk \\ Asimina Vasalou \\ UCL Knowledge Lab \\ London, United Kingdom \\ a.vasalou@ucl.ac.uk
}

\begin{abstract}
Given the significant potential of shared book reading to promote children's learning, the design of e-books has focused on maximising this learning experience. However, recent studies have begun to show that shared reading is a broader opportunity for the family to spend quality time together. Our study aims to explore this perspective further, focusing on the types of parent-child interactions during shared reading and the ways in which shared reading may foster intimacy when parents and children read digital books. We used cultural probes and contextual interviews to capture the shared reading experiences of 7 parents and 6 children in their homes. We discuss the different nuances of the shared reading practices identified. We use these findings to suggest new design opportunities that support the complex practices of shared reading with technologies at home.
\end{abstract}

\section{Author Keywords}

Shared reading; parent-child reading; families; cultural probes; digital books

\section{CSS Concepts}

Human-centered computing Interaction design theory, concepts and paradigms

\section{INTRODUCTION}

Cumulative research evidence suggests that parent-child reading of books constitutes a unique context that supports both children's learning and parent-child bonding [44]. On the one hand, children's books are a source of languagestimulating material that parents use to expand children's understanding of the wider world and their own lives. Adults' reading strategies, for instance those that make connections between the book's texts and illustrations or the child's life through asking questions and eliciting a conversation, can significantly advance children's language and literacy skills [47]. On the other hand, shared reading is by most families perceived as an emotionally positive experience, facilitating parent-child bonding [36].
The advent of digital books and the ubiquitous presence of digital technologies in the home (see e.g. $[10,29]$ ) raise the question of how technology can be designed to support parent-child shared reading. Thus far, research on the design and use of children's digital books has focused on the learning opportunities engendered during shared reading $[16,27]$. For example, Troseth et al. [43] found that the introduction of prompts and scaffolding questions for parents into an interactive book led to increased parent-child conversation during the reading session. With its focus on children's learning, however, research has not yet considered the design opportunities that may exist for parent-child bonding in the context of shared reading. Though parents report learning as one of the reasons that motivate shared reading with their children, they also approach shared reading as quality time with their family that provides them with a sense of enjoyment in seeing their children thrive [25].

In this paper we take the view that shared reading is a relational intimate act that fits in the social fabric of family life. In aiming to identify new opportunities for design, we seek to understand the perspective of both parent and child, focusing in particular on the situated practices that underpin shared reading at home. A study with six families was carried out where we combined cultural probes with contextual interviews to understand reading in the home context in more depth. Our paper makes three theoretical contributions. First, we show that bonding is a mutually recognised outcome by both parents and children, and valued above and beyond the learning focus of shared reading. Second, we find that the child's agency over their book choice is seen as critical by both children and parents, but at times, parents face tensions with other equally important values that lead them to limit children's book choices. Third, we show that although children engage in the stories they choose, there is a need to engage their parents as well, particularly in more complex meanings and multi-layered story plots. We connect and problematise each of these themes in light of existing children's reading technologies and propose new design 
opportunities for family's digital reading, which we critically reflect on to inform future work in this emerging area.

\section{BACKGROUND}

Shared book reading is one of the most researched literacy activities in the home context, with numerous studies documenting its benefits for children's language, literacy and academic development. The benefits also include social and emotional knowledge development [40] that are sustained over time [25]. Parent-child shared reading has thus been described as an essential learning experience that supports children's emotional (e.g. [12]), cognitive [6] and academic [46] competences.

With the advent of digital books in early 2010s, the research attention has shifted to shared reading with e-books, story apps and interactive digital books. Researchers interested in this area have often compared print books and e-books in relation to various learning outcomes and parent-child dialogue. These studies have identified both positive and negative influence of e-books. For example, Smeets and Bus [36] found that children's reading of e-books facilitated the children's learning but Krcmar and Cingel [19] found that e-books, in comparison to print books, diminished the children's reading comprehension and learning. Yet another two studies found that both e-books and print books supported children's learning with little difference between the two formats on children's learning [23, 27]. There are several possible explanations for these mixed findings, including different types of book designs used for the comparison, different methods followed by the researchers and different age groups studied. Another significant factor is parents' attitudes and familiarity with e-books.

With respect to parents' attitudes, descriptive and survey data indicate that parents strongly prefer print to digital books [34, 39] and parents actively support their children's choice of print but not digital books for reading at home [42]. Despite the wide availability of digital devices in most Western households and their frequent use by children as young as two years, there is little e-reading happening at home. In a national UK survey, parents have reported strong concerns about their children's engagement with digital books, including the concern of increased screen time, lack of educational content and inappropriate design for children's quiet reading time [20].

The latter concern has been corroborated by research that shows that highly interactive digital books disrupt the dialogue between parents and children during shared reading and negatively affect the child's learning from the session or the parents' enjoyment of it [8, 31]. However, digital books that are purposefully designed to meaningfully engage the child in a learning experience can increase their learning from the session [26] and create a positive reading experience for both the parent and child [21]. This perspective has motivated a body of design research that considers how interactive digital books can be designed to best support parent-child dialogue that fosters the child's learning (e.g. [7, 9]).

Taking a holistic view to the study of parental perceptions around the purposes of shared reading, Nicholas and Paatsch [28] report that parents' desire to foster their child's learning is one of several motivating factors. Parents value the importance of facilitating their child's language and literacy development, but parents read with their children also in order to derive enjoyment from seeing them thrive and to spend quality time together, especially during bedtime where children calm down. Dalsgaard et al.'s [11] empirical account of intimacy in family life is particularly relevant for this notion. Their research of four families shows that commitment to family life comes from meaningful joint activities between family members. Parents identify settings that bring them closer physically and emotionally with their children, with children seeking out these opportunities as well. Compared to the symmetrical nature that such acts suggest, intimacy is also expressed through care and a sense of parental responsibility toward the child. Accordingly, parents take on a mentor and tutor role to support their child's academic and emotional development. Applying this lens of intimacy to the findings of Nicholas and Paatsch [28] suggests that shared reading benefits both child and parent, with the child's learning being one aspect of a more complex intimate act. Yet comparatively to the abundant research into shared reading for learning, much less is understood about the type of parent-child emotional interaction that occurs during shared reading and the ways in which this interaction may foster intimacy in the family.

Given the significance of shared reading in fostering parentchild intimacy [28], we wanted to identify the possibilities for designing new digital books that would continue to bring together parents and children around a shared reading experience. Corresponding to typical routines followed in Western families, the research on shared reading has focused on children of pre-school age, who are beginning to learn to read before starting school. We were keen to understand the potential of digital books for slightly older children, that is children between the ages of five and six, who are at a critical transition age to independent reading. Moreover, five-to-sixyear-old children typically engage with digital technologies and reading materials on their own. With the exception of Troseth et al. [43], who included 3-4 year-old children, to our knowledge no study has considered the possibility of designing digital books to provide a joint reading experience for parents and children of 5-6-year olds. Compared to past research in this area that has investigated the relational nature of shared reading with digital technology through behavioural observations e.g. [9, 49] we approached shared reading as a relational and also co-constructed activity and thus we wanted to understand the perspectives of parents as well as their children. This was particularly important in order to reveal the multiplicity of reasons and ways in which parents and children make sense of their reading together. The design study we report next was exploratory in nature. 
We aimed to understand the shared reading experiences of parents and children at home through the use of the cultural probes method.

\section{METHODOLOGY}

\section{Participants}

Six families from the greater London area, United Kingdom, took part in the study. The children were aged between five to six years; there were 3 girls and 3 boys. They were all attending primary school.

\section{The Smith Family}

The Smith Family consisted of a mother (P1a), a father (P1b), a girl aged 5 (C1) and a boy aged 2. Both parents participated in the research together with their daughter who was in the last year of pre-school. The parents were of Greek origin and spoke Greek at home. At the time of the interview, the child wasn't able to read. One or both parents usually read with their daughter in the evening before going to bed for 20 minutes. This occurred on the sofa, or in the child's bed.

\section{The Jones Family}

The Jones Family included a mother, a father, and two boys of 6 and 8 years. The mother (P2) took part in the study with the younger son (C2) who was in the first year of primary school. The family was Hungarian, and similarly to the first family, they spoke their native language at home. The child was able to read age-appropriate books slowly and was gradually moving to autonomous reading. The boy mostly read with his mother or brother. The three usually read together every evening before going to bed for 15 minutes.

\section{The Williams Family}

The Williams Family consisted of a mother (P3), and her daughter (C3) aged 6 who was attending the second year of primary school. The family was British, and they spoke English at home. The child was an independent and accurate reader, and she was able to read books written for older children. The two read together every evening for 15-20 minutes. Usually, this happened in the child's bed. However, if they were reading a book that was particularly engaging, they additionally read after breakfast, and after school.

\section{The Taylor Family}

The Taylor Family included a mother, and two twin boys aged 6 attending the first year of primary school. One of the two children (P3) took part in the study along with the mother (P4). The family was African, and they usually spoke English at home. The child was able to read early readers books autonomously. Often, the three read together in the evening in the children's bed for about 10 minutes. Sometimes, they also read in the afternoon after school.

\section{The Davies Family}

The Davies Family consisted of a father, a mother and a 5 year old girl in Year 1. The father (P5) and child (C5) participated in the study. The family was originally from Sri Lanka, and practiced Sinhala at home. The child was able to read early readers books appropriate for her reading age, and enjoyed reading. The father and daughter usually read together in the child's bed every evening for 20-30 minutes.

\section{The Roberts Family}

The Roberts Family included a Mexican mother, a Greek father, a boy aged 6 and two twin boys of 4 years. The mother (P6) and the older son (C6) participated in the study. The family spoke both Spanish and Greek at home. The child was able to read early readers books autonomously, and sometimes read books to his brothers. The mother usually read with the children in bed every evening for 20-30 minutes.

\section{Study Design and Procedure}

Similar to work by Dalsgaard et al. [11] and Vetere et al. [45] who carried out design research with families, we were drawn to cultural probes. Cultural probes are a creative, reflective and interpretive method for collecting culturallysituated data in context [4]. Cultural probes have been found to engage participants in creative playful activities that can provoke unexpected responses [12]. This was deemed to be particularly important in order to actively engage the children in the research. Moreover, by asking parents and children to co-create the probes, we hoped this method would facilitate our participants' reflections around the interconnected nature of their shared reading, which we wanted to explore. Cultural probes also provided us with a way to access the intimate spaces of shared reading in the home, which has been previously identified to be a particular challenge in this type of research [11]. We chose to combine cultural probes with semi-structured interviews. The interviews served the purpose of clarifying the cultural probe returns and their meaning, and also provided the opportunity to prompt our participants for further reflections.

The participants were recruited using a snowball sampling method [15]: information about the study was sent via email to the researchers' personal contacts and was also shared via Twitter. Interested participants were contacted via email, followed by a telephone call or personal meeting during which the details of the study were explained and information sheets and consent forms were shared with the parents. Upon consent, the researcher delivered a cultural probe kit to the participants' homes. Participants were instructed to engage with the cultural probe kit for a period of 2-3 weeks, and during this time, they maintained contact with the researchers via email. Upon completion of the tasks included in the cultural probe kit, the researcher visited participants at home and conducted a semi-structured interview with the parents and their children. The interview was audio-recorded and lasted between 35 and 45 minutes. The artefacts created by the participants were used as discussion prompts during the interviews. For example, the postcards created by the participants were used to prompt them to talk about their favourite books, and to scaffold the 
conversation around the ways in which parents and children read them together. More broadly, the interviews allowed participants to explain and describe their creations in an open and flexible way, supporting us to develop insights into the nuances of their shared reading practices.

\section{Cultural probe kit}

The cultural probe kit consisted of a set of open-ended materials that the participants could use to express, explore and convey their meanings about three topics/tasks suggested by the researchers. The kits contained a collection of materials intended for the creation of creative artefacts. The materials included: white postcards, coloured paper of various dimensions, stickers, pencils, stamps, treasure chests, glue, fabric, wooden sticks, pompoms and other decorative elements (see Figure 1). The three tasks were supposed to be completed together by the parents and children.

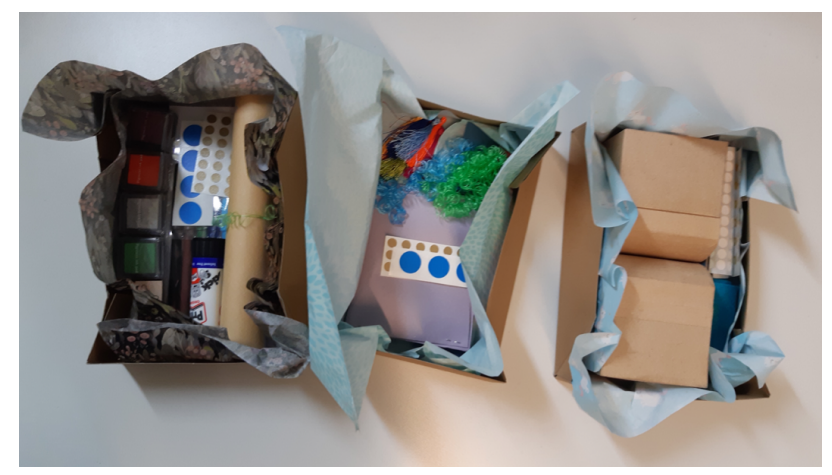

Figure 1. Cultural probe kits given to each family. From left to right: Task 1 (Convincing powers), Task 2 (The magic bookmark), Task 3 (The secret treasure of family reading).

Task 1: Convincing powers - "Your best friend does not like reading and you want to change his or her mind! Design a postcard to send of a book you love reading together with your mum and dad. Why do you like it? How does it make you feel?" This first task aimed to capture the type of books children and their parents enjoyed reading together, and the reasons motivating their choices.

Task 2: The magic bookmark - "When a book has many pages, you use a bookmark to find your place in the book. Design a new bookmark with superpowers that you can use when you read together with your mum or dad. How will it act? How will it look? Will it make new sounds?" The second task invited participants to take a generative view on their shared reading to identify how technology could be used to strengthen their practice.

Task 3: The secret treasure of family reading - "When two people read together, they sometimes enjoy different bits of the same story. Hide your most favourite story bits in your 'child' or 'parent' treasure chest using paper, cloths, pompoms and anything that inspires you!" The third task focused on one story the pair enjoyed together. The aim was to facilitate the articulation of their shared, or individual, engagement in the story in the context of shared reading.

\section{Analysis}

The dataset consisted of transcriptions of the audio-recorded interviews, photographs of participants' creative artefacts and the researcher's fieldnotes taken during or immediately after each home visit. This dataset was analysed following the Collaborative Qualitative Analysis process described by Richards and Hemphill [33]. First, all the four authors coded the first and second interview independently in an inductive way, using open coding to identify discrete concepts and patterns in the data. Second, axial coding was performed to make connections between the patterns identified in the first step [38]. During research meetings, the team discussed the codes and memos created to agree on a shared codebook, which was then applied to the rest of the data and iteratively refined if new codes emerged. Gradually, the codebook was developed into a thematic structure comprising main themes and subthemes relevant to our research questions. The next section reports three main themes identified in our interviews with parents and children about their attitudes, perceptions and preferences concerning shared reading at home.

\section{FINDINGS}

\section{Theme 1 . Shared reading as bonding time}

Parents from all six families reported engaging in shared reading for the child's benefit and learning, with the aim of fostering the child's reading skills and autonomy when engaging with literacy materials. Depending on the age and reading level of the child, the parents reported that they supported and scaffolded the reading process in different ways to make sure that their child was able to understand complex words, comprehend their meaning and make sense of the story. This was illustrated by P5 who reflected on his own role in the child's transition toward an independent reader.

P5: So initially like I said it was reading for her, but now... she's reading, but more simple books. And sometimes it's a combination of things. She starts reading, gets stuck with a word, or, you know sometimes keeps on reading the words but sometimes getting the meaning of a word, what is said in a sentence, she misses it so then I have to help her out in that part. So, that's how we do mostly. Now it's more than me reading to her. It's sort of a combination. Me reading with her and her reading to me. So that's how it is going now.

Nonetheless, while parents engaged in shared reading to support children's literacy development, most parents approached shared reading as an opportunity to foster a close relationship with their child. This was expressed by four out of the six parents who described how their daily shared reading practice with their children represented an 


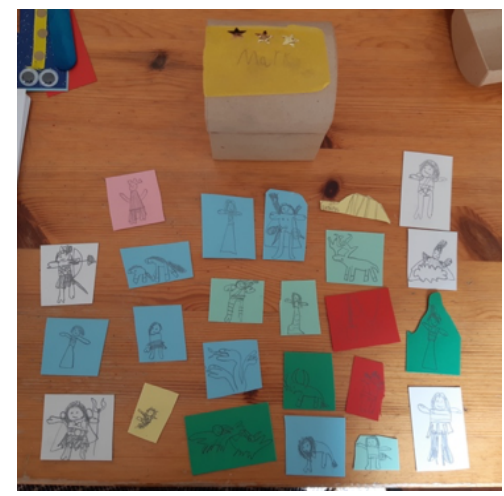

Figure 2a (C5, task 3): The myth of Hercules

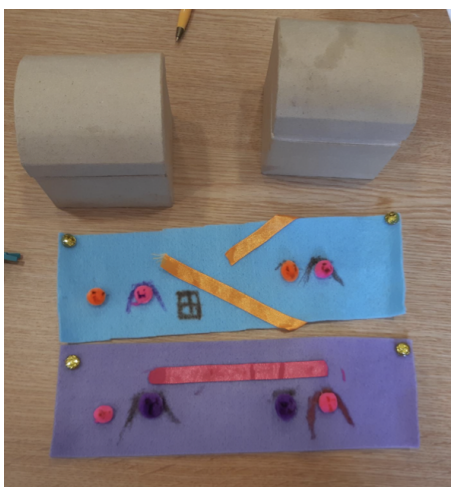

Figure 2b (C5, task 3): Olaf's Amazing Adventures

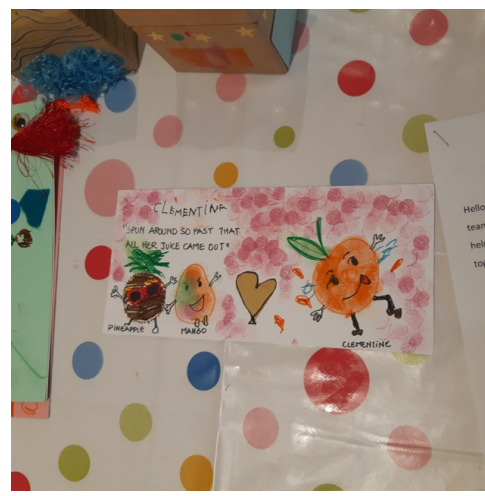

Figure 2c (C1, task 1): Kitchen Disco opportunity to spend quality time together. The participants reported that their lives were usually divided between demanding jobs and housework, and that they therefore had limited time to spend with their children each day. Despite this, shared reading was highlighted as an important daily routine lasting between 10 and 30 minutes in the evening before bedtime. For instance, when prompted to reflect on the value of shared reading, though P5 had earlier reflected on the gradual scaffolding of his daughter's reading, he focused on the importance of shared reading as a joint activity that brought the family together.

$\mathrm{R}$ : Do you see reading together as something to do together or more for education?

P5: Mostly doing together [...] I like it. And I think it's a good way of spending time with her.

Similarly, another parent highlighted the value of this daily moment with his children.

P1b: I enjoy it because I don't spend much time with them during the day so it's a good moment before going to bed.

Children also valued this closeness and recognised shared reading as a context that represented time spent with their parents sitting next to each other and talking about books. The children expressed this through their behaviour by prompting their parents to read stories to them, especially during bedtime, despite some of them already being independent readers. This trend is illustrated by $\mathrm{P} 4$ who described how her children demand for shared reading in the evenings.

\section{$\mathrm{R}$ : OK so who initiates the reading? Is it you or is it them?}

P4: For school reading I do but bedtime they usually ask "can you read us a book?"

Shared reading as bonding time was performed consistently across the families we interviewed. Taking place mostly during bedtime, families read while sitting on the sofa or with the parents sitting by their children's bed, ensuring physical closeness. As P1a explained, this physical closeness was part of the affective expression shared during the reading experience: "On the sofa mainly and they like the bed, that's where we read... It's a cuddling thing, it's not that we are apart... Reading a book is always cuddling, lying with Mummy and Daddy reading a book". Moreover, parents took care in how they verbally narrated stories to their children to facilitate intimacy. As P1a additionally reflected, these narrative acts demarcated a shift away from the tensions of the day: "And the voice of the parents is also nice I think... Because sometimes we are tired and we are stressed we have to go to school... And the tone of voice I mean I understand it if we are stressed or tired while when we read books our voice changes it becomes tender, we are active and we make funny voices... they see the best side of us I think..."

Theme 2. The significance of the child's agency in book choice

All participating parents were keen to foster the child's interest to read for pleasure and they described the importance of children choosing books that aligned with their personal interests. This was ensured by making available interesting book choices at home, and promoting the child to select a book from the home library. P5 explained: "She's the one that selects what she wants to read. Because at home, in the apartment, we have the books. And from that, she would collect what she wants to read." As two of the parents conveyed, the opportunity to choose what is read was pivotal to avoid boredom and foster the child's intrinsic motivation in reading. P2: "[...] They can choose... otherwise it becomes a bit boring, not really motivating... but in the evening you can just choose the books right [addressing the child]? That you like to read together".

Most parents made trips to the bookstore and public libraries to identify books they knew would spark their child's interest. Four parents reported developing a growing home library to ensure the book choices available at home aligned with their child's personal preferences. While for all six parents the book choice was informed by their children's interests, sometimes book choices were also informed by the wider social context of the family. A prominent example was 
shared by P3 who added to the home library a book recommended by a friend and written by an acquaintance. Although the long-term engagement with the book was facilitated by a narrative that bridged parent-child interests, the pair was drawn to the book because of its social significance and relationship to the author, as expressed by the child:

R: Ok so you told me a bit about this book already... so how did you find it?

C3: So, we've got a friend who wrote this book and mommy asked where to buy it for [name of the child]

$R$ : Oh, so it's someone you already know!

C3: Yeah!

R: So do you like it, that someone you already know has written this exciting story...

C3: Yeah, yeah, yeah!

Promoting their child's interest in books and encouraging their child's choice was perceived by parents to be a way for observing outcomes that reflected their values. Most parents emphasised the importance of their children's autonomy and self-direction in reading for pleasure. For example, when asked why she enjoyed the child's favourite book, P6 explained how observing the child become independent and confident in reading represents a great sense of satisfaction derived from shared reading for pleasure with her daughter:

\section{$\mathrm{R}:$ And what did you enjoy about the book?}

P6: That he's reading to me, yeah. I love... that he's getting like fluent now, confident.

Even though all parents attributed critical importance to the child's agency in book choice, book choice was also subject to different negotiations between the parents and children. In households of two or more children where shared reading was a bedtime practice, siblings were often called to negotiate book choices based on their individual story preferences. Other times, parents told us that they reframed the reading activity to focus on specific learning aims. In particular, five of the participating families used shared reading as an opportunity to practice native language skills and teach their children multicultural knowledge. With five out of the six participating families speaking English as a second language at home, this theme seemed to be particularly characteristic of our sample. P1b was especially vocal about his intention to teach his native language and culture to his daughter: "we try to read both in English and Greek so that they [the children] can maintain both languages because we don't know if she [the daughter] will ever learn how to read and write in Greek [...] Sometimes I propose books around Greek mythology so that we can learn something about different names and Olympus and all the others. "In choosing a book for this goal, the parents reported that they sometimes chose the language and subsequently encouraged the child to choose the topic of the story, thus seeking to balance their own goals with the need to promote their child's agency in book choice.

Theme 3. Children's emphasis on the story characters Children showed consistently how their enthusiasm for their favourite stories gains momentum from their involvement with the story characters. Particular story characters attracted children's interest through their roles in the story plot. In all the interviews, children presented their book 'heroes' as central elements for their favourite stories, admiring their strengths and qualities, but also certain physical characteristics such as their hair colour or clothes. The children's descriptions of these elements were the starting point for sharing the story content with the researcher. For example, $\mathrm{C} 2$ described the content of his treasure chest to the researcher (Figure 2a) and while showing his favourite character Hercules, he identified him as "the main character, he runs faster than an arrow!". For the rest of the interview, the child talked enthusiastically about various tasks performed by Hercules and described in vivid detail how Hercules overcame beasts and other obstacles. In another family, C5 similarly described her favourite book with strong references to the main character's hair and magic powers:

R: OK, so, why is it your favourite book?

C: 'Cause I like Elsa a lot.

R: So, is Elsa the main character, right? Why do you like her?

C: Because she has blond hair and she could make snow.

The importance of children's favourite or imaginary story characters was particularly evident in the second probe task, which explicitly encouraged children to envision new ways to engage with the story. One of the children, C3, imagined her story characters coming alive thanks to a "superpower button" on her magic bookmark. During the interview, the child described how she expressed this transformation using a cat stamp included in the cultural probes kit: "... and the characters come alive! [...] So, I put a cat on it to show that!"

The insights presented in the first two themes branched out of participants' artefacts during the interviews, and namely reflected parental perspectives. In contrast, theme 3 reflects the children's accounts and the patterns we observed in their engagement with the cultural probes whilst their verbal descriptions were anchored on literal aspects of their creations. For example, during his interview, C5 referenced his many drawings of different character aspects (e.g. the arrow, Hercules' opponents etc.) to recreate two of his favourite scenes from the story.

Beyond the child's individual engagement with the story, parents constructed their own engagement with their child's story in particular ways. A characteristic that seemed to be especially appreciated by both parents and children was humour and fun, represented by or enacted by their favourite story characters. The first family created two postcards (see 
Figure 2c) that expressed the "funniest" moments in the story. In this example, the scenes that the pair found most entertaining were the ones depicting the characters' peculiar ways of moving and acting. As P1 explained "They are the funniest so Clementine is dancing so fast and that's why it was funny and the mango because we like mango... Pineapple is cool pineapple because he wears glasses in the party and she high-fives the other fruits... her favourite fruit!" However, the child's humour was sparked by the characters, whereas her mother found meaning in seeing her child's joy and engagement when listening to the story.

While children focused on easily noticeable characteristics of their favourite story characters, their parents engaged with more abstract levels of the story, such as metaphors and relationships between the story characters. Out of the six families involved, P3 had chosen to read a book written for older children fostering her immersion and interest in how the story evolved. As P3 explained: "I was excited to see what was next, so it wasn't something like "now I'm going to read her". I think that's quite important, to find something that it's exciting for parents as well. And it's quite hard to find something that does that at that age." The remaining parents struggled to engage with the simple narrative of the stories their children enjoyed, at best engaging with bounded aspects of the story. In an example from the interview with P2, the mother commented on her son's descriptions of the story characters and their adventures pointing out their different interests, highlighting the challenge present in finding stories that appeal to both.

P2: "I remember that too... I remember all these bits as well but I think I am interested in other things because looking at his pictures I'd never remember the arrows... the pig... I think I'm more interested into... I mean he's interested in the action and what happens while I'm more interested in the emotional part, I guess."

\section{DISCUSSION}

The goal of this paper was to explore how parents and children engage in shared reading at home. By applying the method of cultural probes combined with parent and child interviews, we built on previous literature that views parentchild shared reading not only as a context for children's learning, but also as an intimate and enjoyable experience for the family. The methodology we followed was chosen to foreground the voices of children and parents given the coconstructed nature of reading, and to highlight their shared and distinctive accounts. In bridging their perspectives with respect to shared reading practice at home, our findings contribute new insights into the ways in which parents and children engage around books. The discussion that follows presents an interpretive analysis of our findings and raises new design opportunities for digital reading, which we problematise and contextualise against past research.

\section{Bonding around the book}

Past research has shown a relationship between parent and child shared reading, and children's positive development (e.g. $[40,25,12,6,46])$. This perspective has led to the exploration of how digital books can be designed to scaffold children's learning during shared reading moments. In alignment with this literature, the parents in our study recognised the value of shared reading in promoting their children's reading skills and wider knowledge. This prompted them to engage in practices that scaffolded their child's learning. However, even though parents initiated shared reading as a way to promote their child's learning, our study also shows that both parents and children expressed the view that, above all, reading a book was a positive moment to spend together. Shared reading was conceived as an opportunity for parents and children to stay physically close, thus fostering bonding and a positive atmosphere in the family.

The analysis of parents' perspectives has also revealed a point of tension that is underrepresented in the current literature. Namely, while the parents sought moments to read and bond with their children, they were also weary of having to juggle work and household demands. This sometimes led to a lack of motivation to read with their children. While some work has begun to explore how to design for shared reading and family bonding, it has mostly aimed to support relationships at a distance $[24,32]$. In demonstrating the value parents and children ascribe to bonding during reading time, our findings suggest the need to design for collocated parent-child reading that recognise the realities of busy parenthood.

\section{Engendering physical interaction to promote bonding}

When exploring how bonding happens during shared reading, our findings emphasise the essential role of physical closeness. All of the participating parents focused on the physical intimacy they shared with their children during book reading. Physical closeness was facilitated by the spatial arrangements chosen for reading: most of the time, shared reading occurred during bedtime where child and parent were laying together. These observations underline the importance of engaging child and parent in a physical alongside a verbal - interaction. A design example that taps into this relationship is the prototype Kindoma Ltd.'s [18] shared reading technology, which connects parents and children via a video conference call and traces their joint gestures and finger-placements on the book pages in real time. In the context of collocated reading, the possibility to jointly turn the digital page or to use joint physical interaction as input to advance a story, is one way of promoting the importance of embodied engagement during shared reading.

However, the place and time of shared reading also raises a potential tension with the screen-based focus of digital technology for reading. Some research has shown the risks associated with children's exposure to screens later in the day, a concern also voiced by parents $[13,20]$. It is here where HCI research exploring the interplay of the physicaldigital [14] can potentially offer ways of re-thinking how we 
can bridge the analogue book with the digital aspect e.g. through integrating sensors in the physical book that promote shared action.

\section{Supporting the parent in performative storytelling}

In addition to the physical dimension of bonding, our findings show the importance of supporting the process of adult storytelling. Parents shared the intentional ways in which they verbally scaffolded the bonding with their children, with particular attention paid to how the story was narrated and performed. In previous work, Raffle et al. [32] designed Story Play to connect family members at a distance. Using the book as a bonding context, Raffle et al. [32] provided parents with dialogic reading prompts to use with their children. This work offered a potential supplement to the loss of communication caused by geographical displacement, and also recognised the important role of the parent in the bonding process. However, we suggest that future design should also focus on scaffolding oral storytelling by supporting parents on how to best narrate stories to their children. For instance, books could be designed to prompt parents to deliver paralinguistic cues at critical moments within the plot.

\section{Negotiating book choices}

Taken together, our findings show that book choice is a value-driven decision sometimes subject to parent-child negotiations. All children participating in our study regularly chose and read books with their parents that aligned with their interests. Parents held the view that their child's book choice fostered their intrinsic motivation and autonomy in reading. Children's motivation was evidenced through their enthusiasm when they shared their favourite stories with us, especially during the third cultural probes task. To support children's choices, parents created home book libraries aligned with the topics their children were interested in. Even though the children's interests were the most critical factor guiding parents' book choice, in one case, there was evidence of the parent's and child's shared interest in a specific book written by an author familiar to them. This illustrates the importance of paying attention to not only children's own choices of books but also the broader sociocultural values that may frame these choices.

\section{Child agency in content recommender systems}

Applied to the context of digital book libraries, our findings confirm the important role that content recommender systems could play in fostering young children's interest in reading. Kucirkova [22] reviewed most popular children's reading recommender systems in digital libraries and critiqued the ways in which they positioned the child in relation to the book choices they were offered. She argues in favour of an agentic child role where the child can shape the algorithms and their recommendations with their direct input. While our child participants were prepared and supported by their parents to take on this role, we also recognise that the practices we observed were in the context of a highly educated cohort where parental engagement was particularly high. Thus, to add to Kucirkova's analysis of content recommender systems, future work in this space could begin to consider how this technology may be designed to support and scaffold children from different socio-economic backgrounds to take an active role in shaping these choices.

\section{Digital libraries designed for parent-child}

While, as shown by previous research (e.g. [1]) parents highly valued the child's agency to make a book choice, our study additionally revealed a new tension with other values, particularly with parents' desire to promote cultural and language learning in the family. The majority of the parents participating in our study were not native English speakers and were not British. In maintaining the family unit while living in Great Britain, the parents told us that it was important to them to preserve a multicultural identity. Parents facilitated this goal by offering a limited set of book options to their child, focusing on their preferences for what the child should learn from the books. Within this set of book options, however, they let the child choose. The negotiated (cultural) space we observed was the outcome of the participants involved and it adds a new design opportunity.

Our finding that book choice is a negotiated object between parent and child suggests the importance of moving away from a purely personalised model to approaches that support parent-child shared negotiation to find the middle space and a book that is aligned with both partners' preferences. The design of digital libraries that hold large numbers of book titles could benefit from this insight. For example, digital libraries could provide book search with joint keywords and allow parents and children to look for texts that attract both reading partners. To the best of our knowledge, there have been no design efforts in facilitating joint adult-child book choices with digital libraries.

\section{Parental and child perspectives on story engagement}

Our analysis revealed that children and parents engaged in the same story in different ways. While the children engaged with particular aspects of the stories, their parents anchored their shared experience inside and outside the story.

\section{Augmenting book characters to support story elaboration}

There is a growing interest in augmented reality (AR) children's books such as the well-known Magic Book [1], or other AR research prototypes developed by $[17,3]$. Our findings broadly support the value of augmenting book images, and additionally augmented interactions with book characters. Moreover, the detailed ways in which children described their engagement with their favourite stories provides further insight regarding what aspects of stories may be best to augment. Children were particularly drawn to story heroes with a strong or whimsical character, and storylines with humorous twists. The children also paid close attention to the physical appearance of story characters, which was typically conveyed through the books' illustrations. When re-telling their stories to us, the children's starting point was the story character, which then created a context for sharing some aspects of the story plot. 
Previous research has explored how haptic feedback reinforcing story dimensions impacts on child-parent dialogue [9]. It was found that haptic feedback relating to the core plot was the most facilitative of parental prompts that extended the child's understanding of the story. Similarly, our findings suggest that future story augmentations (e.g. haptic, augmented reality) could take story characters as the key point of departure in order to motivate children by building on their strong attachment. Design that recognises this connection may provide important opportunities for children's further dialogue and story elaboration, as we documented in our study and was also evidenced by Cingel and Piper [9].

\section{Intergenerational story generation}

In light of the increasingly ubiquitous and pervasive role of technologies in children's lives, researchers and policymakers have emphasized joint media engagement and co-use of technologies by parents and children to keep families together [5]. In addition to digital games [36] or shared tabletop task space with video chat [48], digital books provide an opportunity for collocated family bonding around a meaningful experience. The idea of a child-parent partnership has been at the centre of joint media engagement. In the context of games, Yen et al. [49] empirically showed that the parent's role in this partnership can vary from bystander, to spectator, coach and teammate. Our findings highlight that the role parents take highly depends on the properties of the book. During shared reading, children mostly focused on literal aspects of the story and they engaged with the characters and story plot in a consistent way. Parents, on the other hand, valued their children's choices and preferences, but did not always enjoy the story plot. Despite this, we found that parents were sometimes immersed in their children's joy and positive experiences, and were less worried about the actual story content. Although parents and children attended to different aspects, there was a joint positive experience, with parents acting as coaches to foster their child's engagement.

However, there were also isolated cases in which parents found opportunities to engage with more complex layers of book content themselves. During these instances, parents' roles were transformed from coaches to teammates who were equally immersed in the same experience as their children. In our data, a strong example of this occurred with books for more advanced readers that included abstract elements and complex emotional relationships between the characters. Recent research has shown that joint media engagement can be underpinned by different goals and consequently, different parent-child dynamics concluding that productive forms of shared engagement are in part malleable by parents and children [49]. Our study exemplifies this by identifying two contrasting parental roles (parent-coach with parentteammate) and their different emotional outcomes.

Further research may aim to promote the role of the parent teammate and explore the ways in which parents and their children engage with the same stories, identifying additional story elements that sparkle the interest of both. This could inform the design of intergenerational books specifically designed for parent-child shared reading, an area that is currently missing in the contemporary reading landscape. However, the finding that advanced books can lead to a closely aligned engagement with the story opens up a new opportunity space for design. Our research was motivated by the lack of digital reading tools for intimate shared reading between children at the brink of reading independence and their parents. It may be that stories for advanced readers constitute that desired hybrid space that would bridge the interests of parents and their children, combine the asymmetrical reading and language skills of both partners, and in doing so, offer a context for adults' active contribution to the reading experience. In establishing the need to intellectually engage both parent and child in the book, we hope our findings inspire further work in this area.

\section{CONCLUSION}

Shared parent-child reading has been identified as an important learning opportunity for young children [44]. In this study, we expanded this view by recognising that shared reading is part of a complex set of intimate practices in the home context. In order to explore how shared reading occurs at home between children and their parents, we combined cultural probes with contextual interviews with six families. Our findings revealed three points of tension. First, whereas bonding was mutually recognised by both parents and children, the parents sometimes struggled to orchestrate and perform their narrator role during shared reading because of their busy schedules. Second, children and their parents recognised in their own ways the vital role of the child's book choice, but at times, the parents faced a tension with other equally important values that led them to limit children's book choices. Third, although children engaged in the stories they chose, their parents often struggled to identify with the same stories and were seeking more complex meanings and multi-layered story plots. By unpacking each of these themes, we identified new opportunities that advance the design of digital technologies for fostering positive parentchild shared reading experiences.

\section{ACKNOWLEDGMENTS}

This research was funded by the EPSRC project 'Dynamic, Real time, On-demand Personalisation for Scaling (DROPS)' under EP/R033838/1. We thank the children and parents for their participation, and our DROPS project partners for their continuing feedback on our research.

\section{REFERENCES}

[1] Jim Anderson, Ann Anderson, Jon Shapiro and Jacqueline Lynch. 2001. Fathers' and mothers' book selection preferences for their four year old children abstract. Reading Horizons, 41, 4. Retrieved December $25^{\text {th }}$, 2019 from https://scholarworks.wmich.edu/reading_horizons/vol4 $1 /$ iss $4 / 1$ 
[2] Mark Billinghurst, Hirokazu Kato and Ivan Poupyrev. 2001. MagicBook. In Proceedings of Extended Abstracts on Human Factors in Computing Systems, $25-$ 26. https://doi.org/10.1145/634086.634087

[3] Amir H. Behzadan and Vineet R. Kamat. 2013. Enabling discovery-based learning in construction using telepresence. Automation in Construction 33, 3-10. https://doi.org/10.1016/j.autcon.2012.09.003

[4] Kirsten Boehner, Janet Vertesi, Phoebe Sengers, Paul Dourish. 2007. How HCI Interprets the Probes. In Proceedings of the SIGCHI Conference on Human Factors in Computing Systems, 1077-1086. https://doi.org/10.1145/1240624.1240789

[5] Alicia Blum-Ross and Sonia Livingstone. 2016. Families and screen time: Current advice and emerging research. Media Policy Brief 17. London: Media Policy Project, London School of Economics and Political Science.

[6] Adriana G. Bus, Marinus H. van IJzendoorn and Anthony D. Pellegrini. 1995. Joint Book Reading Makes for Success in Learning to Read: A Meta-Analysis on Intergenerational Transmission of Literacy. Review of Educational Research 65, 1, 1-21. https://doi.org/10.3102/00346543065001001

[7] Angela Chang and Cynthia Breazeal. 2011. TinkRBook: shared reading interfaces for storytelling. In Proceedings of the 10th International Conference on Interaction Design and Children, 145-148. https://doi.org/10.1145/1999030.1999047

[8] Cynthia Chiong, Jinny Ree, Lori Takeuchi and Ingrid Erickson. 2012. Print Books vs. E-books: Comparing Parent-Child Co-Reading on Print, Basic and Enhanced E-book Platforms. Retrieved September 20th, 2019 from https://www.researchconnections.org/childcare/resourc es/23539

[9] Drew Cingel and Anne Marie Piper. 2017. How Parents Engage Children in Tablet-Based Reading Experiences: An Exploration of Haptic Feedback. In Proceedings of the 2017 ACM Conference on Computer Supported Cooperative Work and Social Computing (CSCW'17), 505-510. https://doi.org/10.1145/2998181.2998240

[10] Common Sense Media. 2017. The Common Sense Census: Media Use by Kids Age Zero to Eight 2017. Retrieved September 20th, 2019 from: https://www.commonsensemedia.org/research/thecommon-sense-census-media-use-by-kids-age-zero-toeight-2017

[11] Thomas Dalsgaard, Mikael B. Skov, Malthe Stougaard, Bo Thomassen. 2006. Mediated Intimacy in Families: Understanding the Relation between Children and Parents. In Proceedings of the 2006 conference on
Interaction design and children, 145-152. https://doi.org/10.1145/1139073.1139110

[12] Book Graham Doyle, Wendie Bramwell. 2006. Promoting Emergent Literacy and Social-Emotional Learning Through Dialogic Reading. The Reading Teacher 59, 6, 554564. https://doi.org/10.1598/RT.59.6.5

[13] Nomathemba Dube, Kaviul Khan, Sarah Loehr, Yen Chu and Paul Veugelers. 2017. The use of entertainment and communication technologies before sleep could affect sleep and weight status: a population-based study among children. International Journal of Behavioral Nutrition and Physical Activity 14, 97. https://doi.org/10.1186/s12966-017-0547-2

[14] Elisa Giaccardi and Elvin Karana. 2015. Foundations of Materials Experience: An Approach for HCI. In Proceedings of the 33rd Annual ACM Conference on Human Factors in Computing Systems, 2447-2456. https://doi.org/10.1145/2702123.2702337

[15] Leo A. Goodman. 1961. Snowball Sampling. The Annals of Mathematical Statistics 32, 1, 148170. https://doi.org/10.4135/9781412963947.n535

[16] Connor Graham, Mark Rouncefield, Martin Gibbs, Frank Vetere and Keith Cheverst. How Probes Work. In Proceedings of the 19th Australasian conference on Computer-Human Interaction: Entertaining User Interfaces, 29, 29-37.

https://doi.org/10.1145/1324892.1324899

[17] Raphael Grasset, Andreas Duenser, Hrtmut Seichter and Mark Billinghurst. 2007. The mixed reality book: a new multimedia reading experience. In Proceedings of the Extended Abstracts on Human Factors in Computing Systems, 1953-1958 https://doi.org/10.1145/1240866.1240931

[18] Kindoma Ltd. 2013. Video. Retrieved September $20^{\text {th }}$, 2019 https:/www.youtube.com/watch?v=Zp4JDE4T1JE

[19] Marina Krcmar and Drew P. Cingel. 2014. Parent-Child Joint Reading in Traditional and Electronic Formats. Media Psychology, 17, 3, 262-281. https://doi.org/10.1080/15213269.2013.840243

[20] Natalia Kucirkova and Karen Littleton. 2016. A National survey of parents' perceptions of and practices in relation to children's reading for pleasure with print and digital books. Retrieved September 20th, 2019 from https://www.booktrust.org.uk/globalassets/resources/re search/digital_reading_survey-final-report-8.2.16.pdf

[21] Natalia Kucirkova, David Messer, Kieron Sheehy and Rosie Flewitt. 2013. Sharing personalised stories on iPads: a close look at one parent-child interaction. Literacy $47, \quad 3, \quad 115$ 122. https://doi.org/10.1111/lit.12003 
[22] Natalia Kucirkova. 2019. The Learning Value of Personalization in Children's Reading Recommendation Systems: What Can We Learn From Constructionism? International Journal of Mobile and Blended Learning (IJMBL) $\quad 11, \quad 4, \quad 80-95$. https://doi.org/10.4018/IJMBL.2019100106

[23] Alexis Re Lauricella, Rachel Barr, Sandra L. Calvert. 2014. Parent-child interactions during traditional and computer storybook reading for children's comprehension: Implications for electronic storybook design. International Journal of Child-Computer Interaction. https://doi.org/10.1016/j.ijcci.2014.07.001

[24] Elaine Massung, Sarah Dickins, James Torbett, James Holmes, Kirsten Cater, Victoria Bates. InTouch Tactile Tales: Haptic Feedback and Long-Distance Storytelling. In Proceedings of the 33rd Annual ACM Conference Extended Abstracts on Human Factors in Computing Systems, 1289-1294 https://doi.org/10.1145/2702613.2732843

[25] Edward C. Melhuish, Mai B. Phan, Kathy Sylva, Pam Sammons, Iram Siraj-Blatchford and Brenda Taggart. 2008. Effects of the Home Learning Environment and Preschool Center Experience upon Literacy and Numeracy Development in Early Primary School. Journal of Social Issues 64, 1, 95-114. https://doi.org/10.1111/j.1540-4560.2008.00550.x

[26] Amelia K Moody, Laura M. Justice, Sonia Q. Cabell. 2010 Electronic versus Traditional Storybooks: Relative Influence on Preschool Children's Engagement and Communication. Journal of Early Childhood Literacy 10, 3, 294-313. http://dx.doi.org/10.1177/1468798410372162

[27] Susan B. Neuman, Kevin M. Wong, Tanya Kaefer. 2017. Content not form predicts oral language comprehension: the influence of the medium on preschoolers' story understanding. Reading and Writing 30, 8, 1753-1771. https://doi.org/10.1007/s11145-0179750-4

[28] Maria Nicholas and Louise Paatsch. Mothers' views on shared reading with their two-year olds using printed and electronic texts: Purpose, confidence and practice. Journal of Early Childhood Literacy, 124.https://doi.org/10.1177/1468798418792614

[29] Ofcom. 2016. Children and Parents: Media Use and Attitudes Report. Retrieved September 20th, 2019 from https://www.ofcom.org.uk/research-and-data/medialiteracy-research/childrens/children-parents-nov16

[30] Tiffany G. Munzer, Alison L. Miller, Heidi M. Weeks, Niko Kaciroti, Jenny Radesky. 2019. Differences in Parent-Toddler Interactions With Electronic Versus Print Books. Pediatrics, 143, 4, e20182012. https://doi.org/10.1542/peds.2018-2012

[31] Julia Parish-Morris, Neha Mahajan, Kathy Hirsh-Pasek, Roberta M. Golinkoff, Molly F. Collins. 2013. Once
Upon a Time: Parent-Child Dialogue and Storybook Reading in the Electronic Era. Mind, Brain and Education $7, \quad 3, \quad 200$ 211. https://doi.org/10.1111/mbe. 12028

[32] Hayes Raffle, Rafael Ballagas, Glenda Revelle, Hiroshi Horii, Sean Follmer, Janet G, Emily Reardon, Koichi Mori, Joseph 'Jofish' Kaye, Mirjana Spasojevic. 2010. Family Story Play: Reading with Young Children (and Elmo) Over a Distance. In Proceedings of the SIGCHI Conference on Human Factors in Computing Systems, 1583-1592. https://doi.org/10.1145/1753326.1753563

[33] Kevin Andrew Richard and Michael A. Hemphill. A practical guide to collaborative data analysis. Journal of Teaching in Physical Education 37, 2, 225-231. https://doi.org/10.1123/jtpe.2017-0084

[34] Anna Richter and Mary L. Courage. 2017. Comparing electronic and paper storybooks for preschoolers: Attention, engagement, and recall. Journal of Applied Developmental Psychology 48, 92-102. https://doi.org/10.1016/j.appdev.2017.01.002

[35] Daisy J.H. Smeets, Adriana G. Bus. 2012. Interactive electronic storybooks for kindergartners to promote vocabulary growth. Journal of Experimental Child Psychology 112, 1, 36-55. https://doi.org/10.1016/j.jecp.2011.12.003

[36] Daisy J.H. Smeets, Adriana G. Bus. 2013. Picture storybooks go digital: Pros and cons. Reading instruction in the age of common core standards, 176189. https://doi.org/10.1598/0496.13

[37] Kiley Sobel, Arpita Bhattacharya, Alexis Hiniker, Jin Ha Lee, Julie A. Kientz, Jason C. Yip. 2017. It wasn't really about the PokéMon: parents' perspectives on a location-based mobile game. In Proceedings of the 2017 CHI Conference on Human Factors in Computing Systems, 1483-1496. https://doi.org/10.1145/3025453.3025761

[38] Anselm Strauss and Juliet Corbin. 1990. Basics of Qualitative Research. Grounded theory procedures and techniques. Sage Publications.

[39] Gabrielle A. Strouse, and Patricia A. Ganea. 2017a. A print book preference: caregivers report higher child enjoyment and more adult-child interactions when reading print than electronic books. International Journal of Child Computer Interaction 12, 8-15. https://doi.org/10.1016/j.ijcci.2017.02.001

[40] Mele Taumoepeau and Ted Ruffman. 2006. Mother and Infant Talk About Mental States Relates to Desire Language and Emotion Understanding. Child Development $\quad 77, \quad 2, \quad 465-481$. https://doi.org/10.1111/j.1467-8624.2006.00882.x

[41] Zsofia K. Takacs, Elise K. Swart, and Adriana G. Bus. 2014. Can the computer replace the adult for storybook reading? A meta-analysis on the effects of multimedia 
stories as compared to sharing print stories with an adult. Frontiers in psychology, 5, 1366. https://dx.doi.org/10.3389/fpsyg.2014.01366

[42] Loori M. Takeuchi and Sarah Vaala. 2014. Level up learning: A national survey on teaching with digital games. Retrieved September 20th, 2019 from https://files.eric.ed.gov/fulltext/ED555585.pdf

[43] Georgene L. Troseth, Gabrielle A. Strouse, Israel Flores, Zachary D Stuckelman, Colleen Russo Johnson. 2019. An enhanced eBook facilitates parent-child talk during shared reading by families of low socioeconomic status. Early Childhood Research Quarterly (In Press). https://doi.org/10.1016/j.ecresq.2019.02.009

[44] Anne van Kleeck, Steven A. Stahl, Eurydice B. Bauer. 2003. On reading books to children: Parents and teachers. Routledge.

[45] Frank Vetere, Hilary Davis, Martin R. Gibbs, Peter Francis, Steve Howard. 2006. A magic box for understanding intergenerational play. In Proceedings of CHI'06 Extended Abstracts on Human Factors in Computing Systems 1475-1480. https://doi.org/10.1145/1125451.1125722

[46] Barrie Wade and Maggie Moore. 2000. A sure start with books. Early Years 20, 2, 39-46. https://doi.org/10.1080/0957514000200205

[47] Barbara A. Wasik and Mary Alice Bond. 2001. Beyond the pages of a book: interactive book reading and language development in preschool classrooms. Journal of educational psychology, 93, 2, 243250. https://doi.org/10.1145/1125451.1125722

[48] Svetlana Yarosh, Anthony Tang, Sanika Mokashi, and Gregory D. Abowd. 2013. Almost touching: parentchild remote communication using the sharetable system. In Proceedings of the 2013 conference on Computer supported cooperative work, 181-192. https://doi.org/10.1145/2441776.2441798

[49] Kate Yen, Yeqi Chen, Yi Cheng, Sijin Chen, Ying-Yu Chen, Yiran Ni, and Alexis Hiniker. 2018. Joint Media Engagement between Parents and Preschoolers in the U.S., China, and Taiwan. In Proceedings of the ACM in Human-Computer Interaction, Vol. 2., Article 192 (November 2018), 19 pages. https://doi.org/10.1145/3274461 